\title{
Preparation, Characterization and Catalytic Activity of Copper(II) Oxide Nanoparticles
}

\author{
Md. Ataur Rahman ${ }^{1}$, A. Z. M. Mainul Islam Mazumder², \\ Md. Mufazzal Hossain ${ }^{* 2}$ and Tajmeri S A Islam \\ ${ }^{1}$ Department of Chemistry, Jagannath University, Dhaka-1100, Bangladesh \\ ${ }^{2}$ Department of Chemistry, Dhaka University, Dhaka-1000, Bangladesh
}

( Received: 18 May 2017 ; Accepted : 20 November 2017)

\begin{abstract}
An environmental benign synthetic route was used for preparation of copper(II) oxide nanoparticles from copper(II) sulphate precursor. Precipitates of copper(II) hydroxide were prepared from $\mathrm{CuSO}_{4} .5 \mathrm{H}_{2} \mathrm{O}$ and $\mathrm{NaOH}$. The product was then calcined at $350{ }^{\circ} \mathrm{C}$ to get the expected copper(II) oxide nanoparticles. Characterization of prepared sample was carried out by scanning electron microscopy (SEM), energy dispersive spectroscopy (EDS), FTIR spectroscopy, X-ray powder diffractometry and reflectance measurement. SEM images show that the particle size was less than $100 \mathrm{~nm}$. It is evident from the EDS analysis that the prepared sample was pure and contains only the atoms of $\mathrm{Cu}$ and $\mathrm{O}$. XRD pattern confirmed the presence of only $\mathrm{CuO}$ in the sample. This result was supported by FTIR spectrum. The prepared $\mathrm{CuO}$ was used to study the adsorption and photodegradation of brilliant red (BR) in aqueous medium. The catalytic activity of $\mathrm{CuO}$ was investigated and compared with that of commercial $\mathrm{CuO}$.
\end{abstract}

Keywords: Copper(II) oxide, Brilliant Red, Adsorptive activity and Photocatalytic activity.

\section{Introduction}

Introduction of nano-technology in the field of material science gives a new dimension in the development of solid state chemistry. Increase in surface area with decrease in particle size is the unique property of particle. Semiconductor nanoparticles are attracting more interest due to their vast application in the field of photocatalysis, optoelectronics, solar cell, water purification, $\mathrm{H}_{2}$ production etc $^{1-3}$.

The oxides of transition metals are an important class of semiconductors, which have applications in magnetic storage media, solar energy transformation, electronics and catalysis $^{4-6}$. Among the oxides of transition metals, copper(II) oxide nanoparticles are of special interest because of their low band gap energy which is in visible range in the electromagnetic spectrum of light. $\mathrm{CuO}$ is a semiconducting compound with a narrow band gap and used for photoconductive and photo thermal applications. ${ }^{7}$ However, the reports on the preparation and characterization of nanocrystalline $\mathrm{CuO}$ are relatively few to some other transition metal oxides such as zinc oxide, titanium dioxide, tin dioxide and iron oxide. Some methods for the preparation of nanocrystalline $\mathrm{CuO}$ have been reported recently such as the sonochemical $\operatorname{method}^{8}$, sol gel technique ${ }^{9}$, one step solid state reaction method at room temperature $^{10}$, electrochemical method $^{11}$, thermal decomposition of precursors and co-implantation of metal and oxygen ions and so on. In 1993 Hai-Yan, Yu-Ling, Jing-Kui, and Si-Shen published a preparative method for ultrafine $\mathrm{CuO}$ particles utilizing deposition of an aqueous $\mathrm{CuO}$ sol onto a $\mathrm{SrTiO}_{3}$ substrate. ${ }^{12}$ In 1997 Kakihata, Usami, Yamamoto and Shibata published a route to $\mathrm{CuO}$ powder from copper chloride by a precipitation stripping method. The average particle size for the resultant $\mathrm{CuO}$ was found by laser light scattering to be about $600 \mathrm{~nm}$. In 1998 Dianzeng, Jianqun, and Xi reported on a solid-state reaction between copper chloride and sodium hydroxide to prepare copper(II) oxide. ${ }^{13}$

\section{Experimental}

Preparation of copper(II) oxide from copper(II) sulphate

A solution of $\mathrm{CuSO}_{4} .5 \mathrm{H}_{2} \mathrm{O}$ was prepared in a beaker and $1 \mathrm{M}$ solution of $\mathrm{NaOH}$ was added to it with continuous stirring. A blue precipitate was formed. The solution was kept for half an hour and a few more drops of $\mathrm{NaOH}$ were added for complete precipitation. Finally the blue precipitate of $\mathrm{Cu}(\mathrm{OH})_{2}$ was separated by filtration and washed several times by deionized water to make it neutral. The precipitate was collected in a watch glass and dried in an oven at about $95^{\circ} \mathrm{C}$. After that, it was grained into powder by a mortar. The powder was taken in a dry, empty porcelain dish. To calcine the powder the dish was put in a muffle furnace and the temperature of the furnace was maintained in the range of $350^{\circ} \mathrm{C}-360^{\circ} \mathrm{C}$ for three hours.

\section{Characterization of prepared copper(II) oxide}

Surface morphology, particle size, stoichiometry, functional groups, crystallinity and band gap energy of the prepared copper(II) oxide were investigated by scanning electron microscopy, energy dispersive X-Ray spectrometer, Fourier transform infrared spectrophotometer, X-ray diffractometer and reflectance measurement.

\section{Adsorptive and photocatalytic activity of oxide}

$0.10 \mathrm{~g}$ prepared $\mathrm{CuO}$ was added to the $90.0 \mathrm{~mL}$ water to prepare suspension and it was kept overnight so that particles can soak water. $10.0 \mathrm{~mL}$ of brilliant red (BR) solution was to the suspension in a $100 \mathrm{~mL}$ beaker. To study the adsorption, in absence of light the beaker containing suspension was placed on a magnetic stirrer in the lamp house. Initial concentration of BR was determined by taking little amount of suspension in a semi-micro test tube just after mixing. After that, suspensions were collected in test tubes at different times and centrifuged at a constant speed for 30 minutes to obtain clear solution. The absorbance of these centrifugates was measured at $\lambda_{\max }$ of $\mathrm{BR}$ using deionized water as reference. The $\mathrm{pH}$ of deionized water was kept same as $\mathrm{pH}$ of suspension. Experiments were carried out in ambient temperature. Amount of BR adsorbed on copper(II) oxide was calculated using the following equation

\footnotetext{
Author for correspondence. e-mail: mufazzal@ du.ac.bd
} 


$$
q_{t}=\left(C_{i}-C_{t}\right) \times \frac{V}{W}
$$

where, $C_{i}$ and $C_{t}$ are the concentrations of $\mathrm{BR}\left(\mathrm{mg}^{-1} \mathrm{~L}^{-1}\right)$ at zero time and at time $t . V$ is the volume of the suspension in litter and $W$ is the weight of $\mathrm{CuO}$ in $\mathrm{g}$. Concentration of $\mathrm{BR}$ in suspension was calculated using Beer- Lambert Law. The amount adsorbed was plotted as a function of time in Fig. 6(a).

The photocatalytic activity of the prepared copper(II) oxide was investigated by irradiating the suspension with ultraviolet light (wavelength $\sim 254 \mathrm{~nm}$ ) in a closed lamp house, inner walls of which were covered with aluminium foil to prevent the loss of light by absorption. Before irradiation the suspension was agitated for an hour to reach the equilibrium of adsorption in dark. The suspension was collected and investigated in the same way as done during adsorption study.

\section{Results and Discussion}

The formation of copper(II) oxide follows simple chemical reactions;

$\mathrm{CuSO}_{4}(\mathrm{aq})+\mathrm{NaOH}(\mathrm{aq})=\mathrm{Cu}(\mathrm{OH})_{2}(\mathrm{~s}) \downarrow+\mathrm{Na}_{2} \mathrm{SO}_{4}(\mathrm{aq})$

$\mathrm{Cu}(\mathrm{OH})_{2}(\mathrm{~s}) \stackrel{\Delta}{\rightarrow} \mathrm{CuO}(\mathrm{s})+\mathrm{H}_{2} \mathrm{O}(\mathrm{g})$

\section{SEM image and EDS spectrum of copper(II) oxide}
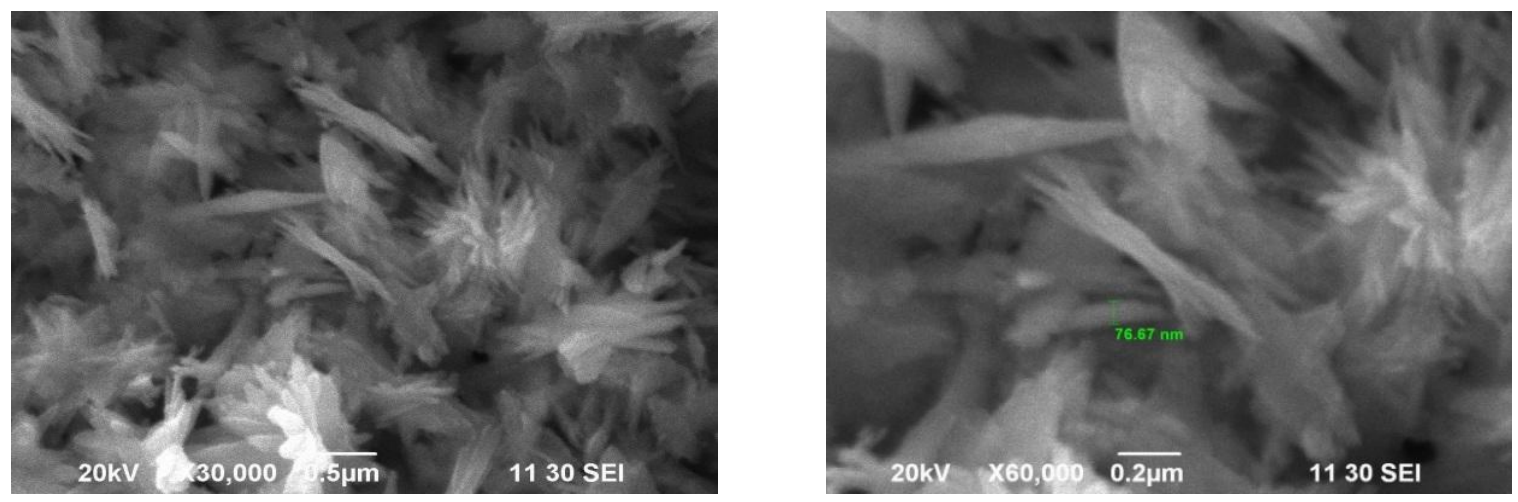

Fig. 1(a). SEM image of prepared copper(II) oxide at 30000 and 60000 magnification.
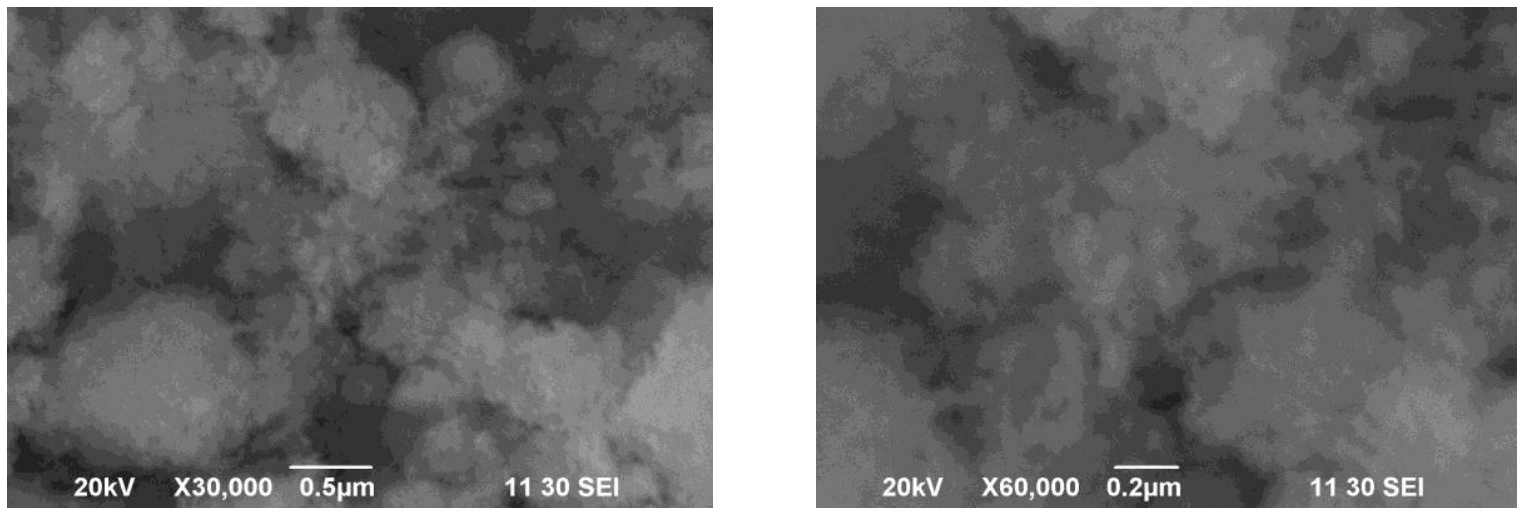

Fig. 1(b). SEM image of commercial copper(II) oxide at 30000 and 60000 magnification.

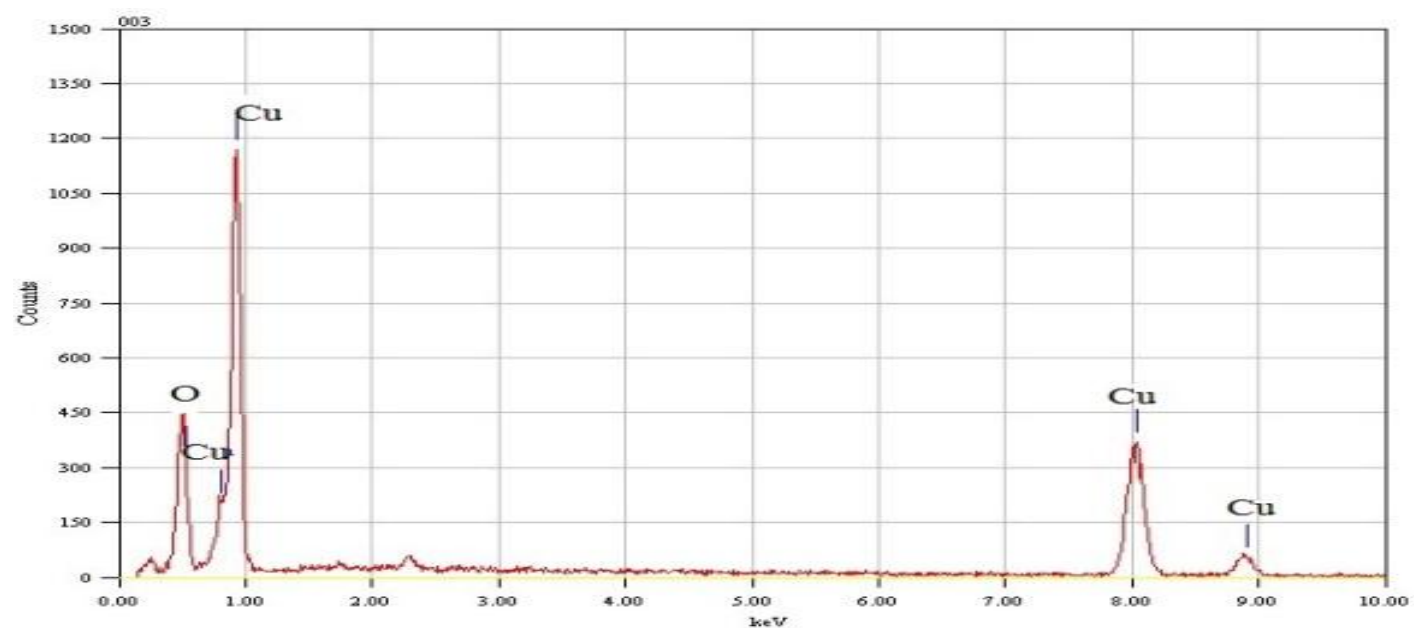

Fig. 2. EDS spectrum of copper(II) oxide 
The morphology of the $\mathrm{CuO}$ powder was examined by SEM. The SEM images in Fig. 1(a) show the fibrous shape of particles and the diameter of the particle of $\mathrm{CuO}$ has been estimated to be $76.67 \mathrm{~nm}$ approximately at 60000 magnification. SEM images in Fig. 1(b) of commercial copper(II) oxide indicate that particles are mostly coagulated and form lumps.

The EDS spectrum shows the peaks only for $\mathrm{Cu}$ and $\mathrm{O}$ atoms which bear the evidence of purity of the oxide sample (Fig. 2). The abundance of $\mathrm{Cu}$ and $\mathrm{O}$ atoms in the sample was shown to be 52.84 and 47.16 respectively by the ZAF standerdless method. This result suggests that the sample is $\mathrm{CuO}$.

\section{FTIR spectrum of copper(II) oxide}

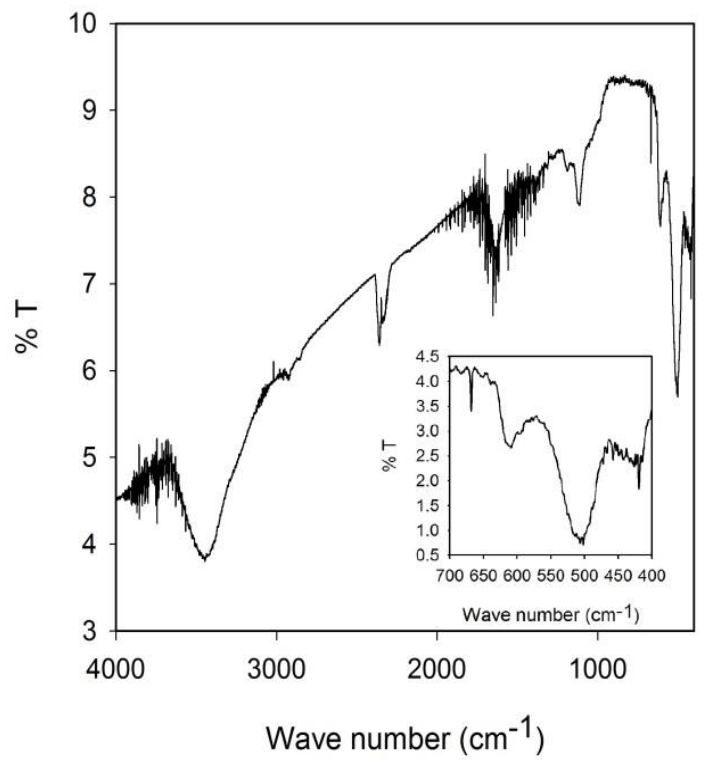

Fig. 3. FTIR spectrum of copper(II) oxide.

The peaks at $1650 \mathrm{~cm}^{-1}$ and $3438 \mathrm{~cm}^{-1}$ in FTIR spectrum were due to $\mathrm{H}-\mathrm{O}-\mathrm{H}$ bending and $\mathrm{O}-\mathrm{H}$ stretching vibration (Fig. 3). Due to the presence of atmospheric $\mathrm{CO}_{2}$, a weak band appeared at about $2300 \mathrm{~cm}^{-1} .{ }^{14}$ The stretching mode of vibration of $\mathrm{C}=\mathrm{O}$ is observed at $1640 \mathrm{~cm}^{-1}$. The bands at about $419.3 \mathrm{~cm}^{-1}, 506.8 \mathrm{~cm}^{-1}$ and $612.6 \mathrm{~cm}^{-1}$ have been assigned to the stretching mode of vibrations of $\mathrm{Cu}-\mathrm{O} .{ }^{15-17}$ Absorption bands at $668.7 \mathrm{~cm}^{-1}$ and $1114.5 \mathrm{~cm}^{-1}$ were due to the $\mathrm{SO}_{4}{ }^{2-}$ bending and stretching vibration respectively. ${ }^{18,19}$ Hence the prepared copper(II) oxide sample contains trace amount of impurities.

\section{XRD pattern of copper(II) oxide}

The XRD peaks can be indexed as monoclinic $\mathrm{CuO}$ (Fig. 4) (space group C2/c; JCPDS cards no. 48-1548). According to the standard XRD pattern of the $\mathrm{CuO}$ powder, the peaks at $35.5498^{\circ}, 38.7624^{\circ}, 48.7916^{\circ}$ and $58.354^{\circ}$ can be endorsed to the Miller indexes of $(-111),(200),(-202)$ and $(202) .{ }^{20}$ No reflections from impurities $\left(\mathrm{Cu}(\mathrm{OH})_{2}\right.$ or $\left.\mathrm{Cu}_{2} \mathrm{O}\right)$ were detected in the sample. In this case, the indexed diffraction rings can be again attributed to (-111), (200), (-202) and
(202) planes of monoclinic $\mathrm{CuO}$.

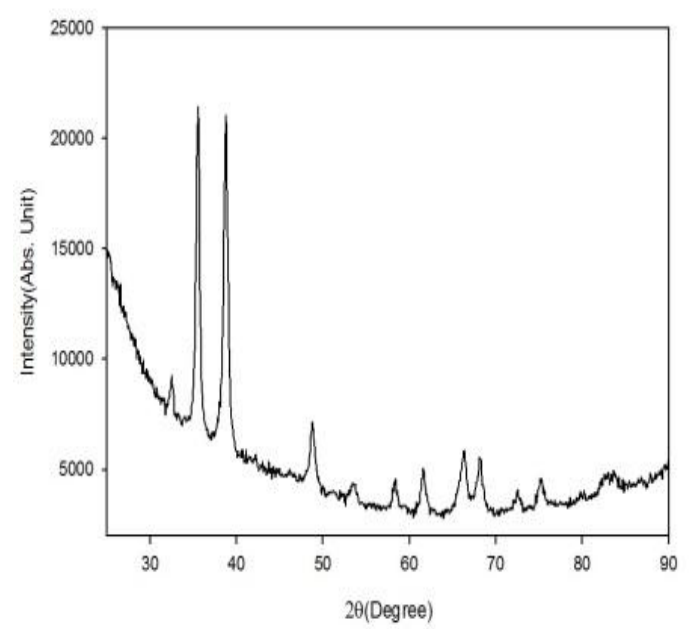

Fig. 4. XRD pattern of $\mathrm{CuO}$.

\section{Reflectance spectrum of copper(II) oxide}

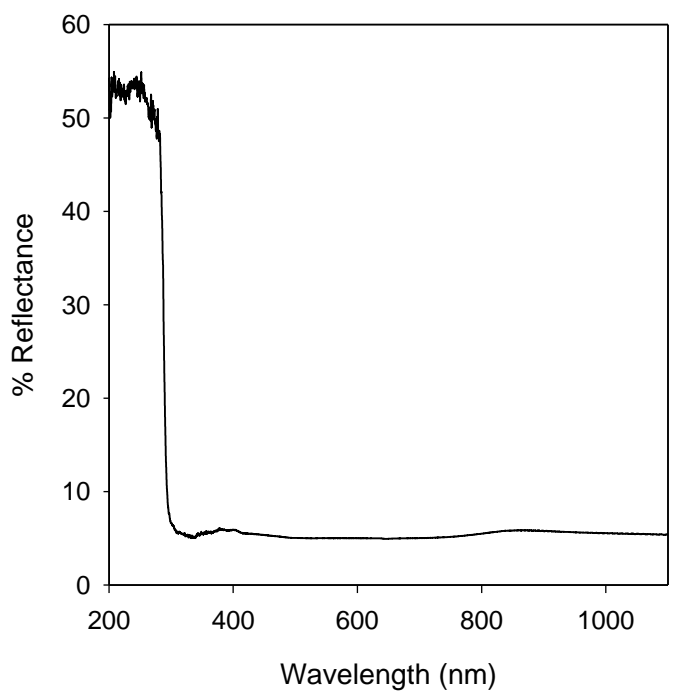

Fig. 5. Reflectance measurement of the prepared copper(II) oxide.

Fig. 5 shows a sharp increase of the reflectance at $300 \mathrm{~nm}$. This characteristics of reflectance spectrum may be attributed to the band gap energy of the prepared copper(II) oxide. $^{21}$

\section{Adsorptive activity}

Adsorption is the major prerequisite condition for any heterogeneous catalytic reaction. The extent of adsorption greatly depends on the particle size of the catalyst and the degree of interaction between the catalyst surface and the dye molecules. It was found from SEM images that $\mathrm{CuO}$ nanoparticles are fiber in shape and the average diameter of $\mathrm{CuO}$ nanoparticles was determined to be $76.67 \mathrm{~nm}$. Adsorption of BR on prepared copper(II) oxide and commercial copper(II) oxide at $\mathrm{pH} 6.20$ under same experimental conditions is shown in Fig. 6(a). Comparative 
catalytic activity of prepared copper(II) oxide and commercial copper(II) oxide is shown in Fig. 6(b). Amount adsorbed of BR on prepared copper(II) oxide at experimental conditions is $32.23 \mathrm{mg} / \mathrm{g}$ and for commercial copper(II) oxide is $28.15 \mathrm{mg} / \mathrm{g}$.

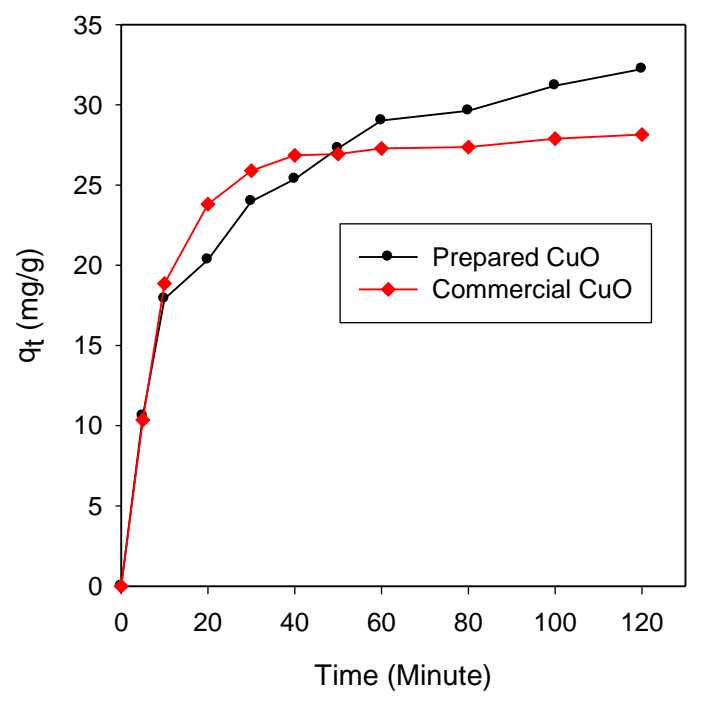

Fig. 6(a). Change of amount adsorbed of $\mathrm{BR}$ on $\mathrm{CuO}$ with time for the initial concentration of $36.92 \mathrm{mgL}^{-1}$ at $\mathrm{pH} 6.20$.

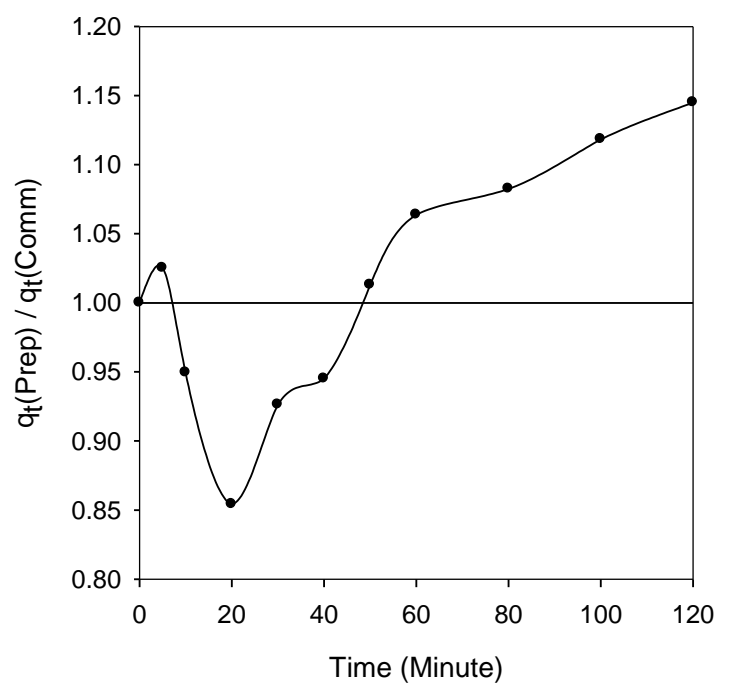

Fig. 6(b). Ratio of amount adsorbed of BR on prepared and commercial $\mathrm{CuO}$ with time at same conditions.

Adsorptive activity of prepared copper(II) oxide is about 1.15 times higher than that of commercial copper(II) oxide. This enhanced adsorptive activity of prepared copper(II) oxide is mainly due to the particle size of the prepared oxide and which is in nano-scale. Adsorptive activity of adsorbent increases with the decrease of particle size because with the decrease of particle size effective surface area increases. In Fig. 6(b), the ratio $\mathrm{q}_{\mathrm{t}}($ prep. $) / \mathrm{q}_{\mathrm{t}}$ (comm.) is plotted against time interval to understand the way of changing the adsorptive activity of both the samples. At the beginning the $\mathrm{q}_{\mathrm{t}(\text { prep.). }}$ is slightly higher than $\mathrm{q}_{\mathrm{t}(\mathrm{comm} .)}$ but soon after nearly ten minutes the ratio becomes unity suggesting that the adsorptive activity of both the samples becomes equal. During next twenty minutes the sharp decrease of the ratio suggests the increased adsorption on commercial oxide which is due to the adsorption of BR molecules on heterogeneous surface of the lumps of commercial oxide. Soon after twenty minutes the ratio starts increasing and becomes unity again after fifty minutes.Finally beyond fifty minutes adsorptive activity of prepared oxide increases and overcomes that of commercial oxide and sharp increase is observed with time. The slow adsorption of BR on prepared oxide in the beginning is due to its fibrous shape of particles.As the time passes adsorption increases because of smaller size and higher surface area of particles.

\section{Photocatalytic activity}

From the spectrum of Fig. 7, it is evident that absorbance does not change significantly with the irradiation time of the degradation of BR in the suspension of prepared copper(II) oxide. The result shows that the BR undergoes only $4 \%$ degradation during one hour irradiation. It means $\mathrm{CuO}$ is not advisable to use as photocatalyst to the degradation of dye unless the experimental conditions are changed or surface of the oxide is modified.

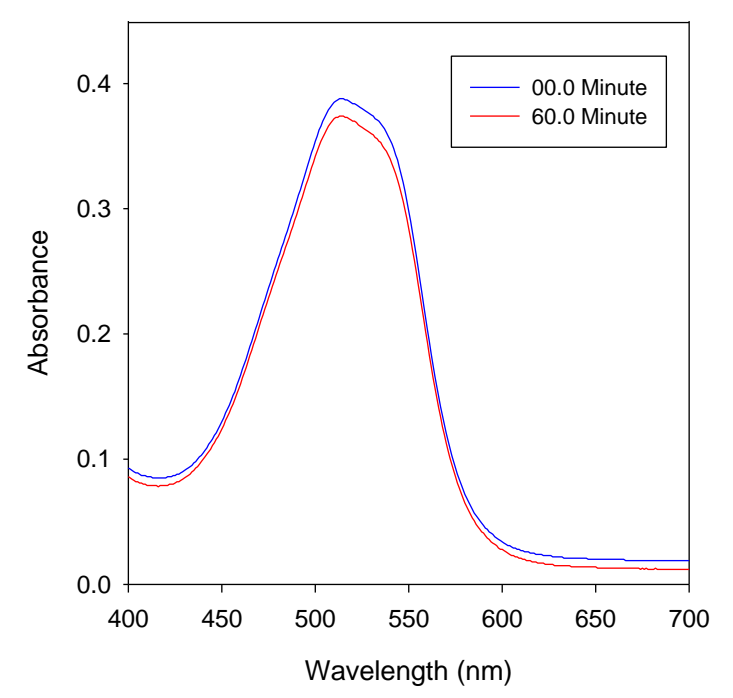

Fig. 7. Spectrum for the degradation of BR in the suspension of prepared copper(II) oxide at $\mathrm{pH} 6.20$ in different times in presence of ultra-violet light.

Tajmeri S. A. Islam et al. ${ }^{22}$ has investigated that the composite of $\mathrm{CuO}$ and $\mathrm{Cu}_{2} \mathrm{O}$ is an efficient photocatalyst for Methylene blue. 95.5\% of Methylene blue has been found to be degraded in presence of visible light during three hours irradiation. The $\mathrm{CuO}$ aerogel $\left(80 \% \mathrm{Cu}^{\mathrm{I}}+15 \% \mathrm{Cu}^{\mathrm{II}}+5 \%\right.$ $\mathrm{Cu}^{0}$ ) mediated degradation of nitrophenols by irradiation under solar simulator was also investigated by J. Bandara, J. Kiwi. ${ }^{23}$

\section{Conclusion}

In the present investigation $\mathrm{CuO}$ have been prepared from copper(II) sulphate and characterized by different techniques e.g. SEM, EDX, XRD FTIR and also by reflectance measurement. SEM image of the prepared 
copper(II) oxide shows that diameter of the particle is about $76.67 \mathrm{~nm}$. EDS result suggests that copper(II) oxide is quite pure. FTIR and XRD pattern are also consistent with literature value.

Adsorption of BR on copper(II) oxide shows that adsorptive activity of prepared copper(II) oxide is about 1.15 times higher than that of commercial copper(II) oxide. This enhanced adsorptive activity is mainly due to the nano-size particles of the prepared copper(II) oxide, which has larger surface area.

\section{References}

1. Lanje A. S., R. S. Ningthoujam, S. J. Shrama, R. K.Vatsa and R. B. Pode, 2010. Luminescence properties of $\mathrm{Sn}_{1-\mathrm{x}} \mathrm{Fe}_{\mathrm{x}} \mathrm{O}_{2}$ Nanoparticles. Int. J. Nanotechnol. 7, 979-988.

2. Mitsuyu T., O. Yamakazi, K. Ohji and K.Wasa, 1982. Piezoelectric thin films of zinc oxide for saw Devices. Ferroelectrics. 42, 233-240.

3. Bjoerksten U., J. Moser and M. Gratzel, 1994. Photoelectrochemical Studies on Nanocrystalline Hematite Films. Chem. Mater. 6, 858-863.

4. Dow W. P. and T. J. Huang, 1996. Yttria-Stabilized Zirconia Supported Copper Oxide Catalyst: II. Effect of Oxygen Vacancy of Support on Catalytic Activity for CO Oxidation. J. Catal. 160, 171-182.

5. Larsson P. O., A. Andersson, R. L. Wallengerg and B. Svensson, 1996. Combustion of CO and Toluene; Characterisation of Copper Oxide Supported on Titania and Activity Comparisons with Supported Cobalt, Iron, and Manganese Oxide. J. Catal. 163, 279-293.

6. Jiang Y., S. Decker, C. Mohs and K. J. Klabunde, 1998. Catalytic Solid State Reactions on the Surface of Nanoscale Metal Oxide Particles. J. Catal. 180, 24-35.

7. Rakhshni A. E., 1986. Preparation, characteristics and photovoltaic properties of cuprous oxide a review. Solid State Electron. 29, 7-17.

8. Kumar R. V., Y. Diamant and A. Gedanken, 2000. Sonochemical Synthesis and Characterization of Nanometer Size Transition Metal Oxides from Metal Acetates. Chem. Mater. 12, 2301-2305.

9. Eliseev A. A., A. V. Lukashin, A. A. Vertegel, L. I. Heifets, A. I. Zhirov and Y. D. Tretyakov, 2000. Complexes of $\mathrm{Cu}$ (II) with polyvinyl alcohol as precursors for the preparation of $\mathrm{CuO} / \mathrm{SiO}_{2}$ nanocomposites. Mater. Res. Innov. 3, 308-312.

10. Xu J. F., W. Ji, Z. X. Shen, S. H. Tang, X. R. Ye, D. Z. Jia and X. Q. Xin, 2000. Preparation and Characterization of CuO Nanocrystals. J. Solid State Chem. 147, 516-519.
11. Borgohain K., J. B. Singh, M. V. Rama Rao, T. Shripathi and S. Mahamuni, 2000. Quantum size effects in $\mathrm{CuO}$ nanoparticles. Phys. Rev. 61, 11093.

12. Hai-Yan D., Z. Yu-Ling, L. Jing-Kui and X. Si-Shen, 1993. Structural features and mechanism of crystallization of $\mathrm{CuO}$ ultrafine particles. J. Mater. Sci. 28, 5176-5178.

13. Dianzeng, J., Y. Jianqun and X. Xi, 1998. Synthesis of $\mathrm{CuO}$ nanometer powder by one step solid state reaction at room temperature. Chin. Sci. Bull. 43, 571-573.

14. Darezereshki E. and F. Bakhtiari, 2011. A novel technique to synthesis of tenorite $(\mathrm{CuO})$ nanoparticles from low concentration $\mathrm{CuSO}_{4}$ solution. J. Min. Metall. Sect. BMetall.47, 73-78.

15. Guedes M., J. M. F. Ferreira and A. C. Ferro, 2009. A study on the aqueous dispersion mechanism of $\mathrm{CuO}$ powders using Tiron. J. Colloid Interf. Sci. 330, 119-124.

16. Chen L., L. Li and G. Li, 2008. Synthesis of $\mathrm{CuO}$ nanorods and their catalytic activity in the thermal decomposition of ammonium perchlorate. J. Alloys. Compd. 464, 532-536.

17. Fernandes D. M., R. Silva, A. A. W. Hechenleitner, E. Radovanovic, M. A. C. Melo and E. A. G. Pineda, Mater. 2009. Synthesis and characterization of $\mathrm{ZnO}, \mathrm{CuO}$ and a mixed $\mathrm{Zn}$ and $\mathrm{Cu}$ oxide Chem. Phys. 115, 110-115.

18. Ohanishi M., I. Kusachi, S. Kobayashi and J. Yamakawa, 2007. Mineral chemistry of schulenbergite and its Zndominant analogue from the Hirao mine, Osaka, Japan. $J$. miner. Petrol. Sci. 102, 233-239.

19. Campo E. J. A., M. Peiteado, A. C. Caballero, M. Villegas and J.E. Rodriguez-Paez, 2009. Room temperature synthesis of high purity $2 \mathrm{D} \mathrm{ZnO}$ nanoneedles. J. Ceram. Process. Res. 10, 477-481.

20. Fuentes S., R. A. Zárate, P. Muñoz, and D. E. Díaz-droguett, 2010. Formation of hierarchical $\mathrm{CuO}$ nanowires on a copper surface via a room temperature solution immersion process. $J$. Chil. Chem. Soc. 55, 147-149.

21. Srikant V. and D. R. Clarke, 1998. On the optical band gap of zinc oxide. J. Appl. Phys., 83, 5447-545.

22. Rahman M. A. and T. S.A. Islam, 2016 Synthesis and Characterization of Copper Oxide Composite and Study of Composite Mediated Photo-Oxidative Degradation of Methylene Blue under Visible Light. International Letters of Chemistry, Physics and Astronomy. 63, 29-35.

23. Bandara J., J. Kiwi, C. Pulgarin and P. Peringer, 1996. Novel Cyclic Process Mediatedby Copper Oxides Active in the Degradation of Nitrophenols: Implications for the Natural Cycle. Environ. Sci. Technol. 30, 1261-1267. 
